\title{
Discussões acerca da necessidade de instalação de colônias agrícolas no sul de Mato Grosso (1889-1920).
}

\section{Discussions about the need for installation of agricultural colonies in southern Mato Grosso (1889-1920).}

\section{Vinicius Rajão da Fonseca ${ }^{1}$}

Resumo: O presente artigo tem como objetivo fazer uma discussão entre a configuração da fronteira no sul de Mato Grosso nas décadas finais do século XIX e os discursos sobre a necessidade da colonização do estado, através da instalação de núcleos coloniais agrícolas. Essa análise foi feita com base na colônia de Terenos, a primeira experiência de colonização pública no estado. Para tanto, utilizaremos como fonte os relatórios de presidente de estado e intendência. A partir da análise, podemos perceber que ao longo do período citado, os governantes mato-grossenses criaram um discurso acerca da indispensabilidade de colonizar o território, baseando-se em argumentos como a deficiência das vias de comunicação, pequena produção agrícola, entre outros fatores.

Palavras-chave: Colonização, discurso, Mato Grosso.
Abstract: This article aims to make a discussion between the setting of the border in southern Mato Grosso in the final decades of the nineteenth century and the discourse on the need of the colonization of the state by installing agricultural colonial settlements. This analysis was based on Terenos colony, the first experience of public settlement in the state. To do so, we will use the reports as a source of state president and stewardship. From the analysis, we can see that along the cited period, Mato Grosso rulers created a discourse about the indispensability of colonizing the territory, based on arguments such as the deficiency of communication channels, small farming, among other factors.

Keywords: Colonization, discourse, Mato Grosso.

\footnotetext{
${ }^{1}$ Licenciado em História pela Universidade Federal de Mato Groso do Sul (UFMS) e mestrando em História, Poder e Práticas Sociais pela Universidade Estadual do Oeste do Paraná (UNIOESTE), campus de Marechal Cândido Rondon. E-mail: [viniciusrajao@gmail.com].
}

Fronteiras: Revista Catarinense de História [on-line], Florianópolis, n.23, p.145-163, 2014. 
Este artigo tem como objetivo analisar os discursos sob os quais se constituiu a ideia da necessidade de instalação de colônias agrícolas no estado de Mato Grosso, entre as décadas finais do século XIX e iniciais do XX. Para tanto, escolhemos como foco central o núcleo colonial de Terenos, por ser considerada uma das primeiras experiências desse modelo no estado. Além disso, queremos compreender o motivo da preferência por imigrantes europeus para a realização desse projeto colonial.

O município de Terenos compreende uma área de $2.841,240 \mathrm{~km}^{2} \mathrm{e}$ situa-se entre " $20^{\circ} 266^{\prime} 31^{\prime}$ " latitude sul e " $54^{\circ} 51^{\prime} 36^{\prime}$ " de longitude oeste a 437 metros acima do nível do mar, distante $27 \mathrm{~km}$ de Campo Grande, capital do Estado de Mato Grosso do Sul, na região Centro-oeste do Brasil. Faz divisa com os municípios de Corguinho, Rochedo, Campo Grande, Sidrolândia, Aquidauana e Dois Irmãos do Buriti².

A preocupação com a instalação de colônias agrícola no estado de Mato Grosso iniciou no final do século XIX, após a instauração do regime republicano, quando o governo mato-grossense criou e regulamentou o Departamento de Terras, Minas e Colonização ${ }^{3}$. Grande parte desses discursos está registrado nos relatórios de Presidente de Estado/Intendência.

Estes políticos possuíam vários interesses, sendo os principais: o preenchimento de "vazios demográficos", o desejo de civilizar o sertão mato-grossense, a ocupação de áreas consideradas estratégicas, a necessidade de aumentar a produção agrícola e o abastecimento de gêneros alimentícios e a ocupação das fronteiras visando garantir a soberania nacional.

Essas expressões estão presentes nos documentos citados acima. Entendo vazios demográficos nesse contexto estudado por regiões "despovoadas" de população branca, no entanto, o estado de Mato Grosso era muito povoado por populações indígenas. $\mathrm{O}$ sertão mato-grossense era visto nesse período por seus governantes e de certa forma pelo restante do país, como uma terra sem lei, afastada do litoral, indomada, de rica natureza a ser desbravada, habitada por índios considerados selvagens, animais bravios, sobre as quais as autoridades tinham pouca informação e controle insuficiente ${ }^{4}$.

${ }^{2}$ RODRIGUES, José Barbosa. Isto é Mato Grosso do Sul: nasce um Estado. São Paulo: Vaner Bícego edições, 1978. p. 105-106.

${ }^{3}$ Lei $^{\circ}{ }^{\circ} 24$ de 16 de novembro de 1892 e decreto ${ }^{\circ} 36$ de 12 de janeiro de 1893.

${ }^{4}$ AMADO, Janaina. Região, Sertão, Nação. Estudos Históricos, Rio de Janeiro, v.8, n.15, p. 145-151, 1995. 
Os trabalhos sobre colônias, colonização e imigração no Brasil são muitos e nos possibilitaram pensar em alternativas e ideias para a realização do estudo. Recentes trabalhos que priorizaram os estados de Mato Grosso e Mato Grosso do sul, constataram que na maioria das vezes, a colonização foi vista como sinônimo de progresso e civilização, carregada de positividade 5 .

Concluíram em suas pesquisas que os espaços a serem colonizados sempre eram representados como fartos em recursos naturais ${ }^{6}$. E a partir do trabalho do colono ideal $^{7}$, nesse contexto, o europeu, ocorreria o crescimento, a expansão, a prosperidade de dado lugar, de dada região.

Pensamos a colonização como um "fenômeno de expansão humana pelo planeta, que desenvolve a ocupação e o povoamento de novas regiões" . De acordo com o pensamento de Alfredo Bosi, a palavra colônia e suas variantes, como coloniais, colonização, colonizadores vieram do verbo latim colo, que significa "eu moro, eu ocupo a terra, eu cultivo"9. Nesse contexto, a palavra colônia passa a ter o sentido de espaço que está sendo ocupado.

Para Bosi, a colonização "é um projeto que engloba todas as forças envolvidas nos significados do verbo colo" 10 , isto é, eu moro, eu ocupo a terra, eu cultivo, logo, colonizar significa "ocupar um novo chão, trazer a memória da terra antiga e transmitir práticas e significados às novas gerações" 11 .

O surgimento da cidade de Terenos ocorreu a partir de uma colonização dirigida primeiramente por uma empresa colonizadora e depois pela associação entre a Intendência de Campo Grande e o governo matogrossense. Em 1920, o poder público estadual firmou um contrato com a empresa Sociedade Territorial Sul-Brasileira Henrique Hacker \& Cia., que

\footnotetext{
5 SANTANA, Daniela. Alianças multifacetadas: colonização de Juara - Mato Grosso: discursos, práticas culturais e memórias (1971-2008). (Dissertação de Mestrado). UFMT, Cuiabá, 2009.

${ }^{6}$ SILVA, Aldina Fernandes. Nas trilhas da memória: uma colônia japonesa no norte de Mato Grosso - gleba Rio Ferro (1950-1960). (Dissertação de Mestrado). UFMT, Cuiabá, 2004.

${ }^{7}$ NAGLIS, Suzana Batista. "Marquei aquele lugar com o suor do meu rosto": os colonos da colônia agrícola nacional de Dourados - CAND - (1943-1960). (Dissertação de Mestrado). UFGD, Dourados, 2008.

${ }^{8}$ SILVA, Kalina Vanderlei; SILVA, Maciel Henrique. Dicionário de conceitos históricos. $2^{a}$ ed. São Paulo: Contexto, 2008. p.67.

${ }^{9}$ BOSI. Alfredo. A dialética da colonização. São Paulo: Cia. Das Letras, 1992. p. 11.

${ }^{10}$ Ibidem, p. 13.

${ }^{11}$ SILVA; SILVA, op. cit., p. 67.
} 
atuava nos estados do Paraná e Santa Catarina para colonizar as áreas margeantes da Estrada de Ferro Noroeste do Brasil.

A empresa recebeu uma área total de 500.000 hectares, dividida em 50 lotes, cada um com 10.000 hectares. De acordo com o contrato e o plano de colonização, a empresa ficou responsável pela organização, divisão e marcação dos lotes, fornecimento de estrutura, além da seleção dos colonos de origem europeia. Após quatro anos do início das atividades, o governo rescindiu o contrato com a empresa, alegando falta de sucesso na colonização, pois durante esse período, o núcleo colonial não passava de cem moradores.

Em 1924, o governo estadual estabeleceu uma parceria com a Intendência de Campo Grande para gerenciar o núcleo colonial. O município passou a pôr em prática o plano de colonização e auxiliar os colonos que chegavam. Em 1929, a colônia foi transformada em distrito ${ }^{12} \mathrm{e}$ em 1953, alcançou a autonomia administrativa transformando-se em município $^{13}$.

Figura 1 - Localização da cidade de Terenos - Mato Grosso do Sul (adaptado).

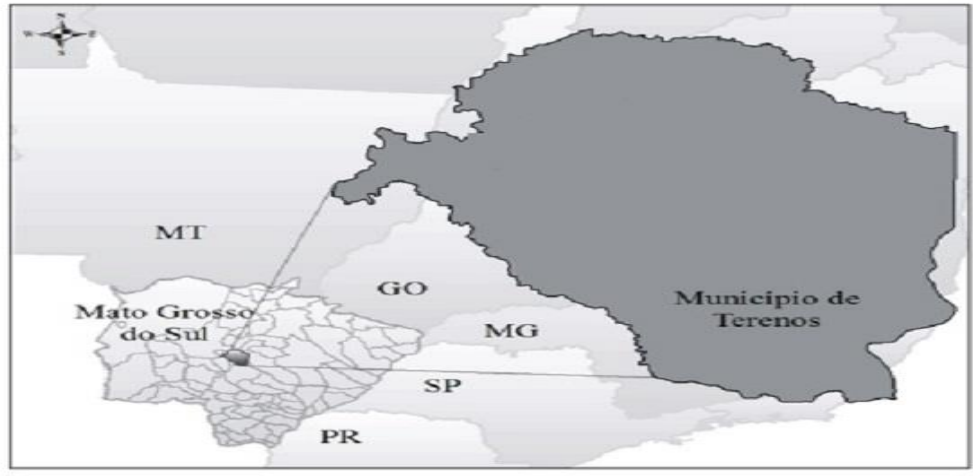

Figura 1. Localização da área em estudo

Fonte: 〈http://www.scielo.br/img/revistas/rbeaa/v14n8/n08a05f01.gif〉. Acesso em 26 maio 2014.

A análise documental nos permitiu refletir e pensar como os governantes mato-grossenses constituíram um discurso acerca da

\footnotetext{
${ }^{12}$ Lei municipal $\mathrm{n}^{\circ} 1021$ de 21 de setembro de 1929.

${ }^{13}$ Lei estadual $n^{\circ} 674$ de 11 de dezembro de 1953.
} 
necessidade de colonizar, povoar e trazer o desenvolvimento para a região sul de Mato Grosso.

Para a realização deste artigo, utilizamos fontes textuais, como os relatórios do presidente de estado e intendência, leis e decretos estaduais acerca da colonização. Todo esse acervo foi produzido pelo governo estadual e municipal nas décadas finais do século XIX e iniciais do XX.

A metodologia nos remete a uma determinada forma de trabalhar, de eleger ou constituir uma pesquisa, de definir as ações de nosso trabalho, ou seja, "a metodologia refere-se a um modo de fazer" ${ }^{14}$, de como agir para vencer as indagações da pesquisa. Em nosso "modo de fazer", utilizamos métodos e técnicas concernentes a uma análise do conjunto da documentação, além do cruzamento e comparação entre as fontes.

Segundo Carlos Bacellar, "a documentação referente ao processo imigratório é bastante ampla e relativamente pouco explorada" e a variedade de documentos são grandes ${ }^{15}$, portanto, necessita-se de um estudo mais sistematizado em relação à temática da colonização.

Portanto, a construção do conhecimento histórico deve-se pautar no desafio de integrar a documentação aos campos teóricos específicos da pesquisa, assim como também o historiador ampliar sua matriz documental, utilizando técnicas, fontes e conhecimento em áreas próximas da História para melhor compreender o passado ${ }^{16}$.

Pensamos a nossa pesquisa a partir da História cultural, como um "espaço de intercâmbio e de debates construídos entre os historiadores que tem como identidade comum a recusa de reduzir os fenômenos históricos a uma só de suas dimensões" 17 , além de "identificar o modo como em diferentes lugares e momentos uma determinada realidade social é construída, pensada, dada a ler" 18 .

A multiplicidade de acepções do termo cultura permitiu a aproximação da História com outras áreas do conhecimento, como a

${ }^{14}$ BARROS, José D'assunção. O projeto de pesquisa em História: da escolha do tema ao quadro teórico. 5a . ed. Petrópolis: Vozes, 2009. p. 80.

15 BACELLAR, Carlos. Uso e mau uso dos arquivos. In: PINSKY, Carla Bassanezi (Org.). Fontes Históricas. $2^{a}$ ed. São Paulo: Contexto, 2010. p. 30-31.

${ }^{16}$ BLOCH, Marc. Apologia da História, ou, o ofício do historiador. Rio de Janeiro: Jorge Zahar Ed., 2001. p. 78-91.

${ }^{17}$ CHARTIER. Roger. A nova História cultural existe? In: LOPES, Antonio Herculano et. al. História e linguagens: texto, imagem, oralidade e representações. Rio de Janeiro: 7 Letras, 2006. p. 29-43.

${ }^{18}$ CHARTIER. Roger. A História cultural entre práticas e representações. Difel, 1990. p. 17. 
Antropologia cultural e a Filosofia. No campo filosófico, um dos pesquisadores que mais trouxeram reflexões metodológicas e que possibilitaram alternativas na produção do conhecimento histórico para os historiadores foi Michel Foucault.

Para Foucault, o que interessava não era a História dos objetos, mas sim, a constituição histórica desses objetos. Por isso, propôs uma História geral, preocupada com a dispersão e o começo em oposição a uma História total, inquieta com a origem, isto é, com as leis gerais que garantem a coesão dos fenômenos ${ }^{19}$.

Assim, o conceito de discurso a partir dos estudos de Foucault ${ }^{20}$ nos serve como uma ferramenta de ajuda na elaboração deste estudo, pois este estudioso entende o discurso como uma estrutura de proposições, termos, crenças e categorias históricas e sociais. O discurso não é somente uma forma de expressão, mas um modo de pensar, de entender, de organizar vidas, instituições e sociedades, de implementar e justificar desigualdades, ou seja, podemos entender como o mundo opera e qual o lugar de cada um nele ${ }^{21}$.

De acordo com Barros, foi "talvez o primeiro a chamar a atenção de maneira mais enfática e claramente enunciada para o fato de que não é a própria sociedade que constitui a realidade a ser estudada, mas sim os discursos que ela produz, ou então suas práticas" ${ }^{22}$. Para Foucault:

em toda a sociedade a produção de discursos é ao mesmo tempo controlada, selecionada, organizada e distribuída por certo número de procedimentos que tem por função conjurar seus poderes e perigos, dominar seu acontecimento aleatório, esquivar sua pesada e temível materialidade ${ }^{23}$.

19 CASTELO BRANCO, Edwar de Alencar. Fazer o que vemos: Michel Foucault - por uma História diagnóstica do presente. História Unisinos, v. 11, n. 3, set./dez. 2007.

${ }^{20}$ A ordem do discurso. São Paulo: Loyola, 1996, História da Sexualidade I: a vontade de saber. Rio de Janeiro, Edições Graal, 1988; Arqueologia do saber. $7^{a}$ ed. Rio de Janeiro: Forense Universitária, 2008; Microfísica do poder. $2^{a}$ ed. Rio de Janeiro: Graal, 1981.

${ }^{21}$ ALBUQUERQUE, Durval Muniz de. Discursos e pronunciamentos: a dimensão retórica da historiografia. In: PINSKY e LUCA; Carla Bassanezi \& Tania Regina (Orgs). O historiador e suas fontes. $1^{\mathrm{a}}$. ed. São Paulo: Contexto, 2011; ORLANDI, Eni. Análise do discurso: princípios e procedimentos. Campinas: Pontes, 1999.

22 BARROS, José D'assunção. O campo da História: especialidades e abordagens. $7^{\mathrm{a}}$ ed. Petrópolis: Rio de Janeiro, 2010. p. 55.

${ }^{23}$ FOUCAULT, 1996, p. 8-9. 
O discurso passa a ser "aquilo pelo que se luta, o poder do qual queremos nos apoderar" 24 . A partir da análise das nossas fontes, queremos compreender como foi a constituição histórica que elegeu a necessidade da colonização de Mato Grosso. Pensar como o núcleo colonial de Terenos foi usado como instrumento para consolidar interesses políticos, econômicos e estratégicos, atendendo as necessidades do Estado.

Entender de que modo características físicas e históricas, como a ideia de vazios demográficos, falta de mão de obra, de povoamento, baixa produção agrícola, poucas vias de comunicação foram utilizadas pelo governo mato-grossense para legitimar o discurso da colonização.

Perceber como a ideia de progresso e civilização foi associada à colonização, ou seja, a instalação de colônias agrícolas seria um fator decisivo, que resolveria os problemas do estado, aumentando a sua densidade, seu povoamento, trazendo melhorias nas vias de comunicações e no abastecimento alimentar.

\section{A configuração da fronteira no sul de Mato Grosso}

A instalação de colônias agrícolas no sul do antigo Mato Grosso $(\mathrm{SMT})^{25}$, esteve inserido num processo de defesa do Estado nacional brasileiro associado a interesses estaduais em fins do século XIX e início do $\mathrm{XX}$, haja vista, ter sido uma região de fronteira que enfrentou numerosos litígios em sua História. Ademais, outros fatores contribuíram para que o governo federal idealizasse um plano que reafirmasse e assegurasse o seu domínio sobre o estado mato-grossense.

A área correspondente aos estados de Mato Grosso e Mato Grosso do Sul foi objeto de disputas seculares que envolveram os países ibéricos durante a colonização do continente sul-americano. Os enfrentamentos continuaram com a formação dos Estados nacionais brasileiro, paraguaio e boliviano, dado que, esse espaço fronteiriço era reputado como essencial para a delimitação das fronteiras dos países, uma vez que, o domínio sobre

\footnotetext{
${ }^{24}$ Ibidem, p. 10.

${ }^{25}$ A porção sul do antigo Mato Grosso foi transformada, em 1977, no estado de Mato Grosso do Sul. Para facilitar a redação e, ao mesmo tempo, evitar o anacronismo, essa porção é referida, neste trabalho, como "sul do antigo Mato Grosso" ou simplesmente SMT. Para mais informações, ver: BITTAR, Marisa. Mato Grosso do Sul: a construção de um estado. Volume I: regionalismo e divisionismo no sul de Mato Grosso. Campo Grande: Ed. UFMS, 2009.
} 
esse território favorecia o controle sobre os rios da região, o que beneficiava seus desempenhos comerciais e suas economias.

Segundo Queiroz, as principais características do território matogrossense ao longo de sua História foram:

vastidão territorial, situação fronteiriça; grande distâncias dos centros dirigentes brasileiros (situados no litoral atlântico); precariedade das vias de comunicação existentes no interior da própria região e entre ela e os ditos centros; população não indígena diminuta e dispersa; estrutura fundiária marcada pela grande propriedade [...] dotada de um débil aparato estatal local ${ }^{26}$.

O estado nacional brasileiro procurou desempenhar um papel para salvaguardar as fronteiras e preservar a unidade territorial do país, buscando adotar estratégias que se destinavam a solucionar as disparidades e as vicissitudes mencionadas acima. Nesse sentido, o elemento humano, isto é, a colonização serviu como um instrumento para a consolidação do domínio sobre o território.

A guerra do Paraguai demonstrou a fragilidade das fronteiras do Brasil, principalmente em relação ao Estado de Mato Grosso. Após a guerra, foi traçado uma meta que visava apontar alternativas e planos para facilitar a integração do estado ao restante do país. Dentre as ações previstas estariam a construção de uma ferrovia para diminuir o tempo de viagem até o estado, o incentivo a colonização para diminuir os supostos vazios demográficos e consequentemente aumentar a produção agrícola do estado ${ }^{27}$.

Após o final da guerra do Paraguai, a atenção dos países platinos voltou-se ao processo de demarcação dos limites territoriais. O tratado da Tríplice Aliança, assinado em 1865 "estipulava que, com a derrota do Paraguai, seriam atendidas as reivindicações territoriais feitas por Brasil e

${ }^{26}$ QUEIROZ, Paulo Roberto Cimó. Temores e esperanças: o antigo sul de Mato Grosso e o Estado nacional brasileiro. In: MARIN, Jérri Roberto; VASCONCELOS, Cláudio Alves (Orgs.). História, região e identidades. Campo Grande: Ed. UFMS, 2003. p. 20.

27 BITTAR, Marisa. Mato Grosso do Sul: a construção de um estado. Volume I: regionalismo e divisionismo no sul de Mato Grosso. Campo Grande: Ed. UFMS, 2009. 
Argentina junto àquela República" 28 . O Brasil exigia a resolução do litígio territorial que envolvia parte do estado mato-grossense, enquanto a Argentina pleiteava ocupar todo o território paraguaio na zona oeste do rio Paraguai.

Ocorreram discordâncias principalmente entre Brasil e Argentina, uma vez que o Império brasileiro recusou aceitar que o país portenho ficasse com as terras do Chaco e o território das missões, pertencentes ao Paraguai para evitar a emergência de uma hegemonia da Argentina no continente. Fazia parte da política externa brasileira garantir a independência do Paraguai e do Uruguai para manter um equilíbrio de poder entre os países da região ${ }^{29}$.

O fim do maior conflito do continente sul-americano também trouxe benefícios para o Brasil e consequentemente para Mato Grosso, pois concedeu o acesso a livre navegação no sistema fluvial Paraná-Paraguai a partir de 1875, ligando o estado do oeste ao litoral brasileiro pelo estuário do Prata.

Esse fator promoveu um afluxo econômico para o SMT, já que permitiu o comércio fluvial, aumentando a exportação do gado e a chegada de produtos de outras localidades. Várias casas comerciais surgiram na cidade portuária de Corumbá, tornando-a um polo no mercado de importação e exportação. Ex-combatentes do conflito com o Paraguai, sejam brasileiros ou paraguaios se estabeleceram no estado, devido aos campos e terras propícias para o desenvolvimento de atividades rurais, como a agricultura, pecuária, charqueada e a exploração dos ervais nativos.

Com o advento da República em 1889, as tensões políticas com a Argentina diminuíram, mas não cessaram. O Brasil procurou praticar uma política de prevenção frente à Argentina, pois existiam rumores que esse país idealizava reconstituir o antigo vice-reinado de Buenos Aires ${ }^{30}$, o que determinava uma ameaça para o Brasil.

Além dos atritos territoriais, ocorreram também desentendimentos nas relações comerciais entre os dois países, no que se refere a questões aduaneiras, destacando o problema relativo ao comércio de trigo. Outro foco de desavença eram as acusações de ambos os países em relação à aquisição

28 QUEIROZ, Paulo Roberto Cimó. As curvas do trem e os meandros do poder: o nascimento da estrada de ferro Noroeste do Brasil (1904-1908). Campo Grande: Editora UFMS, 1997. p. 64.

${ }^{29}$ QUEIROZ, 2003, op. cit., p. 64.

${ }^{30}$ Ibidem, p. 66. 
de armamentos bélicos, o que provocava uma atmosfera de cautela de um para com o outro.

Outro risco compreendido pelo governo federal estava correlacionado a desordem e a fragilidade política no estado, em virtude das lutas coronelistas entre os grupos dirigentes. Nos anos de 1892 e 1906, Mato Grosso se defrontou com duas revoltas violentas que agitaram o país, provocando até o assassinato de seu governador. Esses episódios provocavam sensações de vulnerabilidade na fronteira oeste do Brasil. Nasceram temores de que a Argentina poderia se aproveitar dessas situações de fraqueza do estado para se apoderar da região, incorporando o Mato Grosso ao seu país. Portanto, era necessário que o poder estatal brasileiro se fizesse presente nessa área.

O estado de Mato Grosso era um reflexo da situação nacional, as oligarquias dominaram o cenário político estadual em consonância com a política dos governadores ${ }^{31}$, onde o patriarcalismo familiar predominava nas disputas entre os coronéis.

Entendemos o coronelismo como um sistema político nacional, baseado em barganhas entre o governo e os coronéis. O governo estadual garante, para baixo, o poder do coronel sobre seus dependentes e seus rivais, sobretudo cedendo-lhe o controle dos cargos públicos, desde o delegado de polícia até a professora primária. O coronel hipoteca seu apoio ao governo, sobretudo na forma de votos. Para cima, os governadores dão seu apoio ao presidente da República em troca do reconhecimento deste de seu domínio no estado. $\mathrm{O}$ coronelismo é fase de processo mais longo de relacionamento entre os fazendeiros e o governo ${ }^{32}$.

O caso mais grave foi a revolta de 1906, que do mesmo modo, ocorreu por rivalidade entre os coronéis que dispunham de influência no estado. Esse levante levou o presidente da república Rodrigues Alves determinar a intervenção federal em Mato Grosso, apesar disso, Alves não

${ }^{31}$ Criada pelo presidente Campos Salles, essa política tinha o seguinte funcionamento: o presidente apoiava os governadores estaduais e seus aliados e em troca eles garantiam a eleição para o congresso dos candidatos oficiais. Isso garantia a continuidade das grandes famílias (ricas e poderosas) no poder. Era uma troca entre os governantes estaduais e o governo federal. O governo sustentava os grupos dominantes nos estados, enquanto estes votavam junto com o governo no Congresso Nacional. Os governadores estaduais repetiam o acordo com as lideranças locais (coronéis), que tinham o poder sobre as pessoas de sua região, fazendo com esses votassem de acordo com seus interesses. Sobre o assunto ver: VISCARDI, Claudia Maria Ribeiro. O Teatro das Oligarquias: uma revisão política do café com leite. Belo Horizonte: C/Arte, 2001.

32 CARVAlHO. José Murilo. Mandonismo, Coronelismo, Clientelismo: uma discussão conceitual”. In: Dados, Rio de Janeiro, v. 40, n. 2, p. 2, 1997. 
conseguiu evitar o assassinato de Antônio Paes de Barros, presidente do estado no período ${ }^{33}$.

Esse conflito antagonizou o grupo político do governador Antônio Paes de Barros, também conhecido como Totó Paes e de Generoso Ponce, proprietário de casas comerciais em Corumbá. Esses dois personagens são considerados figuras lendárias no que diz respeito ao coronelismo em Mato Grosso. Em 1906,

Generoso Ponce toma Cuiabá, depõe e mata Totó Paes, apesar da oposição de Rodrigues Alves [...] quando o General Dantas Barreto chega a Cuiabá, em 1906, Totó Paes tinha sido assassinado, e o novo governo é formado pela oposição vitoriosa; Rodrigues Alves nada pode fazer, nem mesmo impor outro governo e castigar os rebeldes ${ }^{34}$.

Esse confronto demonstrou a instabilidade e a deficiência das vias de comunicação do estado mato-grossense com o restante da nação, uma vez que, as tropas federais não conseguiram chegar a tempo de impedir a deposição e a morte de Totó Paes. Quando chegou a Cuiabá, a oposição já havia tomado o poder, tornando-se situação. As forças de intervenção ficaram "retidas por várias horas no estuário do Prata, em decorrência do mau tempo" 35 .

Após o incidente, Dantas Barreto assinalou "sobre a necessidade imediata de uma estrada de ferro que ligasse a capital da República àquele abandonado território nacional" 36 . Em outra passagem, "diz por exemplo o general: oxalá, que o telégrafo e as rápidas vias de comunicação levem a esse despovoado território brasileiro todos os favores da civilização e da paz" 37 .

O governo republicano procurou afirmar seu poder sobre grandes áreas nos confins do território nacional e os investimentos no "telégrafo, acompanhado de estradas e ferrovias, devia abrir caminho para a ocupação produtiva das terras por onde passavam e que estas iniciativas eram fundamentais na ocupação desses novos espaços e na superação das

\footnotetext{
${ }^{33}$ BITTAR, op. cit.

34 CARONE, Edgard. A república velha. Instituições e classes sociais (1889-1930). São Paulo/Rio de Janeiro: DIFEL, 1977. p. 257.

${ }^{35}$ QUEIROZ, 2004, op. cit., p. 117.

${ }^{36}$ BARRETO apud QUEIROZ, 2003, op. cit., p. 118.

${ }^{37}$ Ibidem, p. 128.
} 
fronteiras" 38 . Na república, ocorreu um movimento de "valorização do sertão, seja enquanto espaço a ser incorporado ao esforço civilizatório das elites, seja como referência da autenticidade nacional" ${ }^{39}$. As ferrovias, as linhas telegráficas e as estradas representavam esse esforço civilizatório.

\section{Discussões sobre a necessidade de colonização em Mato Grosso}

Nos relatórios ${ }^{40}$ dos presidentes estaduais do Estado de Mato Grosso no início do século XX até a instalação da colônia de Terenos em 1920, praticamente todos os governantes assinalam em seus pronunciamentos a necessidade urgente da colonização do Estado. Esses discursos expressavam a indispensabilidade de povoar a localidade, de trazer trabalhadores, de integrar o Estado ao restante da nação.

Neste artigo, iremos analisar alguns trechos de relatórios dos presidentes de estado e intendência que expõem a necessidade da importância da colonização no Estado. O presidente Antônio Pedro Alves de Barros em seu relatório no ano de 1901, afirma que:

Os três fatores principais que depende a prosperidade de um estado são: terra, capital e população. Terra temos de natureza verdadeiramente privilegiada e bastante para o estabelecimento de um grande pais; capital temos também se soubermos preservar os fundos indispensáveis para a sua garantia; população, é

38 DOMINGUES, Cesar Machado. A comissão de linhas telegráficas do Mato Grosso ao Amazonas e a integração do Noroeste. In: ENCONTRO REGIONAL DA ANPUH-RIO: MEMÓRIA E PATRIMÔNIO, 14., 2010, Rio de Janeiro. Anais do... Rio de Janeiro: Unirio, 29 a 23 de julho de 2010 , p. 8.

39 LIMA, Nísia Trindade. Um sertão chamado Brasil. Rio de Janeiro: Revan/IUPERJ/UCAM, 1999. p. 65.

${ }^{40}$ Mensagem do presidente do Estado do Mato Grosso Coronel Antônio Pedro Alves de Barros a Assembleia Legislativa de 03 de fevereiro de 1901. Cuiabá. Tipografia oficial; Mensagem do presidente do Estado do Mato Grosso Coronel Antônio Pedro Alves de Barros a Assembleia Legislativa de 03 de fevereiro de 1902. Cuiabá. Tipografia oficial; Mensagem dirigida pelo presidente Joaquim da Costa Marques de 13/05/1913 a assembleia legislativa. Cuiabá. Tipografia oficial; Mensagem dirigida pelo presidente Joaquim da Costa Marques de 13/05/1914 a assembleia legislativa. Cuiabá. Tipografia oficial e Mensagem do presidente do Estado do Mato Grosso Coronel Pedro Celestino Corrêa a Costa a Assembleia Legislativa de 13 de maio de 1911. Cuiabá. Tipografia oficial. 
só abrir, largas as nossas portas e deixar entrar por ela nossos irmãos $[\ldots]^{41}$.

No relatório de 1902, Barros expressa a dificuldade da colonização declarando que "quase nada há a referir sobre o movimento de colonos no findo" 42 . No relatório de 1908, segundo o presidente Generoso Ponce, "também não houve nada naquele período a respeito da colonização"43.

Percebemos que a maioria dos presidentes estaduais almejavam a colonização, porém, a grande maioria não era a favor do investimento público nesse setor, posto que, preferiam as colonizadoras particulares, uma vez que, acreditavam que diminuiriam os custos deixando a cargo das empresas privadas.

O relatório do presidente de estado Joaquim da Costa Marques, enviado à Assembleia em 1913. O político inicia da seguinte forma o tópico sobre o assunto:

Este serviço, de tanta relevância e de incalculável vantagem para o Estado, em que o reduzido número de seus habitantes forma verdadeiro contraste com a vastidão de seu território e a multiplicidade de suas riquezas e onde a escassez de braços para todas as indústrias e trabalhos torne-se dia a dia objeto de sérias preocupações e cria dificuldades invencíveis a todos os empreendimentos. [...] sou de opinião que o que devemos fazer é fomentar e facilitar a imigração espontânea e tentar a fundação de pequenos núcleos coloniais nas proximidades desta capital e de outras cidades $^{44}$.

Esse fragmento nos mostra uma preocupação do presidente Marques relacionado a falta de trabalhadores no estado, porém, ao mesmo tempo,

\footnotetext{
${ }^{41}$ Mensagem do presidente do Estado do Mato Grosso Coronel Antônio Pedro Alves de Barros a Assembleia Legislativa de 02 de fevereiro de 1901. Cuiabá. Tipografia oficial. p. 13.

42 Mensagem do presidente do Estado do Mato Grosso Coronel Antônio Pedro Alves de Barros a Assembleia Legislativa de 03 de fevereiro de 1902. Cuiabá. Tipografia oficial. p. 30 .

${ }^{43}$ Mensagem dirigida pelo presidente coronel Generoso Ponce a assembleia legislativa de 13/05/1908. Cuiabá. Tipografia oficial. p. 31.

${ }^{44}$ Mensagem dirigida pelo presidente Joaquim da Costa Marques de 13/05/1913 a assembleia legislativa. Cuiabá. Tipografia oficial. p. 80.
} 
este ressalta as riquezas naturais, o que nos permite considerar que o governante assinala que a falta de crescimento populacional $\mathrm{e}$ desenvolvimento da região não se deve em razão das possibilidades oferecidas pelo Estado, mas sim pela falta de força humana, que devido ao isolamento do Estado, demoravam chegar. Entendemos também que o investimento público na colonização para esse governante não era prioridade, já que, assinala a necessidade de incentivar a imigração espontânea e não na organização de colônias agrícolas, por exemplo.

Em 1914, Costa Marques novamente em seu relatório afirma:

Está o governo tratando de dar execução a Lei n. 648, de 18 de julho do ano passado, que autorizou o poder executivo a contratar com o Sr. Alvaro Leite a introdução e localização de imigrantes estrangeiros no estado, concedendo, além de outros favores 50.000 hectares de terras devolutas apropriadas a cultura e situadas nas margens ou proximidades de vias-férreas, rios navegáveis e centros populosos e divididos em lotes de 10.000 hectares cada um, destinando-se cada lote a fundação de um núcleo colonial, em que o concessionário é obrigado a introduzir pelo 50 famílias de imigrantes. [...] Parece-me serem estes o meios mais práticos e econômicos para se ir povoando o nosso imenso território, a par da imigração voluntária, que estou certo, tomar grande incremento, assim que tenhamos fáceis vias de comunicação com as zonas mais ricas do estado, e que forem divididos em lotes as terras reservadas para esse fim ${ }^{45}$.

Podemos perceber nas falas dos presidentes de estado algumas semelhanças a respeito da necessidade da colonização do território matogrossense. Afirmam que o estado possuía os elementos fundamentais para a sua prosperidade, como o vasto território, com riquezas naturais que facilitariam o seu desenvolvimento, dispunha de recursos, porém, faltava a população, por isso, se fazia necessário a colonização. Para que isso ocorresse era indispensável à abertura de suas portas no sentido da chegada do "progresso" com a instalação de ferrovias e estradas.

${ }^{45}$ Mensagem dirigida pelo presidente Joaquim da Costa Marques de 13/05/1914 a assembleia legislativa. Cuiabá. Tipografia oficial. p. 41 
Entretanto, a partir da análise dos documentos durante o período de 1900-1920, podemos constatar que a colonização pouco saiu do papel. Podemos pensar que isso ocorreu por alguns motivos, entre eles, até o ano de 1920, verificamos que os presidentes de estado apostavam na colonização espontânea ou a partir de empresas colonizadoras, pois não estavam interessados em onerar as despesas do estado. Somente a partir de 1920, que o presidente Pedro Celestino vai defender a colonização com investimento público, implantando em parceria com a prefeitura de Campo Grande a colônia de Terenos.

Em 1909, o presidente Pedro Celestino, em mensagem dirigida a assembleia, expôs um discurso sobre a necessidade de ocupar as fronteiras do estado. Percebemos que para os governantes do período, Mato Grosso estaria como assinalou José de Souza Martins no "estágio da fronteira", isto é, "se encontram naquele estágio de sua história que as relações sociais e políticas estão, de certo modo, marcadas pelo movimento de expansão demográfica sobre as terras não ocupadas ou insuficientemente ocupadas" 46 .

O movimento de ocupação de fronteiras não é pacífico, é de destruição, de luta, de resistência, marcado pelo desencontro de temporalidades históricas diferentes, como os índios de um lado, e os ditos "civilizados" de outro, do grande proprietário de terra e dos sertanejos, ou seja, "a fronteira é essencialmente o lugar da alteridade" 47 , por isso cada fronteira tem uma realidade diferente, singular e móvel.

Pedro Celestino assinala que o território estava "recheado" 48 de indígenas e que se estes fossem "amansados" 49 poderiam ser incorporados para o trabalho na lavoura, causando uma dicotomia no sentido de o estado estar bastante povoado e ao mesmo tempo vazio, isto é, nos discursos ele é apresentado como vazio, despovoado, no entanto, não é isso que percebemos nas análises documentais.

A expressão amansar é uma "palavra que dá bem a medida do lugar que o índio ocupa no imaginário do civilizado na fronteira: ele é geralmente classificado como animal" ${ }^{50}$, como se fosse um processo de adestramento, mas na verdade é um processo de neutralização, em que os indígenas necessitam se deslocar para o interior na procura de novos espaços. Criou-se

\footnotetext{
${ }^{46}$ MARTINS. José de Souza. Fronteira: a degradação do outro nos confins do humano. São Paulo: Contexto, 2009. p. 132.

${ }^{47}$ Ibidem, p. 133.

${ }^{48}$ Mensagem do presidente do Estado do Mato Grosso Coronel Pedro Celestino Corrêa a Costa a Assembleia Legislativa de 13 de maio de 1911. Cuiabá. Tipografia oficial. p. 21.

${ }^{49}$ Idem.

${ }^{50}$ MARTINS, op. cit., p. 143.
} 
um discurso que parte do pressuposto que o estado estava prestando um favor aos indígenas.

Consideramos importante também a análise e discussão com a obra "Oeste: ensaio sobre a propriedade pastoril", de Nelson Werneck Sodré. O autor nasceu em 1911 no Rio de Janeiro, onde cursou o colégio militar e chegou ao cargo de general. Ministrou aulas na Escola de Comando e Estado Maior do Exército e no Instituto Superior de Estudos Brasileiros.

Sodré publicou diversas obras em vários campos do conhecimento. Escreveu sobre a literatura brasileira, sobre a imprensa, história militar do Brasil e a própria história brasileira. Sodré era do grupo de militares pré1964, ligados ao Partido Comunista Brasileiro e até o golpe civil militar foi um dos principais pensadores marxistas do Brasil ${ }^{51}$.

De acordo com Queiroz, a inspiração para a elaboração da obra "Oeste" veio de uma breve estadia do intelectual no antigo sul Mato Grosso, entre os anos de 1938-1939. Nesse período, Sodré era tenente do Exército brasileiro e executava a função de ajudante de ordens do general José Pessoa. Sodré veio acompanhar o general Pessoa, que foi incumbido para a chefia da $9^{\text {a }}$ Região Militar, sediada em Campo Grande (QUEIROZ, 2009).

Essa discussão foi importante para nosso trabalho, pois Sodré fez várias observações sobre aspectos que analisamos, como o problema do latifúndio, das deficientes vias de comunicação, da pequena produção agrícola, entre outros.

Sobre as vias de comunicação, Sodré realizou os seguintes comentários:

O grande problema do Oeste é o das distâncias. Elas se colocam, entre os pontos em que a civilização construiu alguma coisa, como hiatos enormes, a deprimir os homens, a tornar impossível o contacto das populações, que faz forte uma comunidade e lhe dá a consciência coletiva indispensável às organizações humanas ${ }^{52}$.

\footnotetext{
${ }^{51}$ REIS, José Carlos. Anos 1950: Nelson Werneck Sodré - o sonho da emancipação e da autonomia nacionais. In: As identidades do Brasil: de Vanhargem a FHC. Rio de Janeiro: Fundação Getúlio Vargas, 1999. p. 145-172. SAES, Flávio. Aspectos da obra de Nelson Werneck Sodré (1911-1999). História Econômica \& História de Empresas, v. 2, n. 2, p. 155-163, 1999.

52 SODRÉ, Nelson Werneck. Oeste: ensaio sobre a grande propriedade pastoril. Campo Grande: Editora Alvorada, 2009. p. 33. (Coleção Documentos para a História de Mato Grosso do Sul).
} 
Para resolver o autor, esse problema da integração do estado ao restante do país só foi amenizado com a construção da ferrovia Noroeste do Brasil. Vejamos:

A Noroeste do Brasil vinha resolver um problema geográfico de primeira ordem, em relação ao Oeste: constituiria o vínculo, ainda que tênue, é verdade, que uniria os territórios mato-grossenses ao corpo do Brasil, do qual estavam divorciados, obrigados a depender da via fluvial do rio Paraguai, viável, para nós desde a guerra contra a república do mesmo nome, mas que nos coloca na situação de aceitar a preponderância estranha das forças orientadas para a bacia platina, em lugar de corresponder ao apelo das forças nacionalizadoras que atraem para a zona amazônica ou para os pontos do Atlântico, no litoral paulista ${ }^{53}$.

A sua instalação, trouxe "a possibilidade do escoamento da produção pastoril" do estado, ligando o "sul-mato-grossense à estrutura nacional"; exerceu também "poderosa ação na expansão humana no Oeste", por onde entrava "uma crescente leva de trabalhadores" 54 . Atraiu impulso "a cidades apagadas e mortas" e, ao longo dos trilhos "núcleos urbanos se formariam ou assumiriam desenvolvimento até então desconhecido" 55 .

As palavras de Nelson Werneck Sodré são importantes, pois nos fornecem muitas informações sobre o Mato Grosso no período estudado, porém, se faz necessário tomar suas palavras, sua obra ${ }^{56}$ como um discurso. Não devemos perguntar apenas que informações nos traz, "mas devemos nos perguntar como esse discurso foi produzido, em que época, por quem, em que circunstâncias políticas, econômicas e sociais" 57 ele foi constituído.

Por esse motivo não podemos desconsiderar a fala de Sodré, que era funcionário do estado, do exército brasileiro, seu discurso tem um lugar institucional como diz Certeau ${ }^{58}$, que representa essa instituição, ele [Sodré]

\footnotetext{
53 SODRÉ, op. cit., p. 115.

${ }^{54}$ Ibidem, p. 117.

${ }^{55}$ Idem.

${ }^{56}$ Idem.

${ }^{57}$ ALBUQUERQUE JÚNIOR, Durval Muniz. Discursos e pronunciamentos: a dimensão retórica da historiografia. In: PINSKY, Carla Bassanezi; LUCA, Tania Regina de (Orgs). O historiador e suas fontes. São Paulo: Contexto, 2011. p. 235.

${ }^{58}$ CERTEAU, Michel. Operação historiográfica. In: A escrita da história. Rio de Janeiro: Forense Universitária, 2008.
} 
fala desse lugar. No momento em que assinalou que a ferrovia constituiria o elo entre Mato Grosso e o Brasil, resolvendo um problema geográfico somado a desconfiança com a Argentina, fica aparente a preocupação de uma visão militar, estratégica, de defesa do país. Caso ocorresse um conflito com a Argentina, por exemplo, a ferrovia facilitaria a logística das forças armadas até o local de batalha.

Outra fala importante é o sentido progressista em relação a construção da ferrovia, que resolveria os problemas de ordem econômica, quando assinala que traz uma onda de desenvolvimento para povoados apagados ou mortos, demonstrando o "imaginário que as ferrovias representavam, como portadoras do progresso e da própria história" ${ }^{59}$, como responsável por trazer o moderno e acabar com o arcaico, de conduzir a urbanização no sertão, de levar a civilização para os incivilizados.

Utilizou o termo civilização ao que parece a partir de uma concepção iluminista, onde a cultura é a soma de todos os saberes acumulados e transmitidos pela humanidade. A "civilização deve alcançar toda a humanidade, até os mais selvagens, cabendo aos que estão avançados ajudarem os mais atrasados" ${ }^{60}$. Ou seja, o estado deve se libertar de tudo o que é considerado atrasado, irracional. Observamos uma noção de civilização enquanto progresso coletivo, isto é, uma noção universal de cultura.

\section{Considerações finais}

Nos últimos itens, procuramos demonstrar como se configurou a fronteira no SMT a partir da Guerra da Tríplice Aliança. O governo federal, por meio de várias políticas, procurou fortalecer o domínio sobre o território mato-grossense, que não possuía vias de comunicação terrestres e de fácil acesso com a região sudeste do país, onde se localizava a capital federal.

Buscamos expor os discursos que construíram a imagem de uma fronteira como sendo frágil e as medidas tomadas pelos governantes brasileiros entre o período pós-guerra do Paraguai até o final do Estado Novo em 1945.

A partir da análise dos relatórios dos presidentes estaduais, percebemos que os discursos viam o Mato Grosso como um espaço "desconhecido, inacessível, isolado, perigoso, dominado pela natureza,

\footnotetext{
${ }^{59}$ ARRUDA, GILMAR. Cidades e sertões: entre a memória e a história. Bauru: Edusc, 2000. p. 192. (Coleção História).

${ }^{60}$ CUCHE, Denys. A noção de cultura nas Ciências Sociais. Bauru: Edusc, 1999. p. 22. 
habitados por bárbaros, onde não haviam chegado as benesses da religião, da civilização e da cultura"61, ou seja, era necessário mudar essa situação, expandindo as fronteiras, conhecendo o desconhecido, trazer o progresso, a civilização, colonizar o território, principalmente por povos que eram considerados civilizados e modelos de civilização, como os europeus.

Podemos observar como os discursos e pronunciamentos dos presidentes de estado foram utilizados como artifícios políticos, econômicos e sociais visando atender interesses do estado mato-grossenses, como a ocupação de fronteiras, a civilização do sertão, a melhoria do abastecimento agrícola do estado pautado na necessidade e na instalação de núcleos coloniais agrícolas.

Observamos uma regularidade de falas, que se revelaram argumentos para constituir o discurso da colonização. Destacamos aqui os principais: deficiência da agricultura seja pela baixa produção agrícola, ou pelo método de trabalho empregado; a formação de latifúndios, que impedia a disseminação da pequena propriedade; lucro rápido, oferecido pelo extrativismo e pela pecuária; falta de vias de comunicação para abrir caminhos para escoação da produção e para chegada da força de trabalho e a corrupção que existia no processo de venda e demarcação de terras.

A colônia agrícola de Terenos se inseriu nesse processo de políticas voltadas para a colonização. Após a conclusão da ferrovia Noroeste do Brasil, o governo estadual reservou ao longo do traçado da estrada de ferro, terras visando à instalação de núcleos coloniais, que serviriam para abastecer as cidades próximas. A reserva de terras próxima à ferrovia revelava uma estratégia no sentido de facilitar o escoamento da produção para as cidades. A colônia de Terenos seria um projeto teste, que caso desse certo, serviria de modelo para as seguintes. A colonização assumiria um papel importante para o SMT, o de fortalecer a economia da região e melhorar o seu abastecimento agrícola.

${ }^{61}$ AMADO, op. cit., p. 7. 